\title{
Método Walkley-Black na determinação da matéria orgânica em solos contaminados por chorume
}

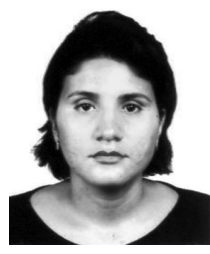

Cibele M. B. Leite ${ }^{1}$, Ricardo S. Bernardes ${ }^{2} \&$ Sebastião A. de Oliveira ${ }^{3}$

\author{
1 UnB. SHCES, QD-807, BL-B, Apt. 401, Cruzeiro Novo, CEP 70655-872, Brasília, DF. Fone: (61) 233-6980. \\ E-mail: cibele.medeiros@zipmail.com.br (Foto) \\ 2 UnB. Campus Univ. Darcy Ribeiro, CP 04508, CEP 70910-900, Brasília, DF. Fone: (61) 307-2325. E-mail: ricardo@unb.br \\ ${ }^{3}$ UnB. Fone: (61) 307-2804. E-mail: oliveira@unb.br
}

Protocolo 186 - 29/11/2002 - Aprovado em 16/12/2003

\begin{abstract}
Resumo: O presente trabalho enfatiza o estudo de verificação sobre a potencialidade do método titulação após oxirredução por via úmida (Walkley-Black) para determinação da matéria orgânica em amostras de solo contaminadas por chorume de resíduos sólidos domésticos. A contaminação das amostras de solo foi realizada em laboratório, utilizando-se chorume com elevada carga orgânica (DOO entre 36.000 a $110.000 \mathrm{mg} \mathrm{L}^{-1}$ ) e dois solos argilosos inorgânicos similares, caracterizados como Latossolo Vermelho (carbono orgânico inferior a 1,4\%). Os resultados mostraram que o método Walkley-Black apresentou potencial para determinação da matéria orgânica proveniente da contaminação do solo com chorume. Para as amostras de solo estudadas, foram obtidos coeficientes de correlação dos valores esperados e dos valores encontrados da matéria orgânica, na faixa de 0,95 a 0,97.
\end{abstract}

Palavras-chave: solo, carbono orgânica, resíduos sólidos

\section{Walkley-Black method for organic matter determination in soils contaminated by leachate}

\begin{abstract}
The present work is related to the study of potentialities of wet oxidation-redox titration (Walkley-Black) method for organic matter determination in soil samples contaminated by leachate from domestic solid wastes. The soil contamination by leachate was obtained experimentally, using leachate with high organic load (chemical oxygen demand ranging between 36.000 to $110.000 \mathrm{mg} \mathrm{L}^{-1}$ ) and two similar inorganic clay soils (organic carbon contents less than 1,4\%), classified as Red Latosol. The results showed that Walkley-Black method has potential for organic matter determination in inorganic clay soil samples contaminated by leachate from domestic solid wastes. The correlation coefficients between expected and determined values ranged from 0.95 to 0.97 in soil samples studied.
\end{abstract}

Key words: soil, organic carbon, leachate, Walkley-Black method, solid wastes

\section{INTRODUÇÃO}

Atualmente, uma das grandes preocupações ambientais está relacionada aos resíduos sólidos gerados pela sociedade moderna e consumista. Com a intensificação do processo industrial, aliado ao crescimento da população e à conseqüente demanda por bens de consumo, o homem tem produzido quantidades significativas de resíduos sólidos sem base numa política clara e efetiva para sua eliminação, incapaz de não gerar prejuízos a si próprio e ao meio ambiente.

No Brasil, a destinação final dos resíduos sólidos constitui sério problema. Segundo dados da PNSB - Pesquisa Nacional de Saneamento 2000 (IBGE, 2002) somente 32,2\% de todos os municípios destinam adequadamente seus resíduos sólidos (13,8\% em aterros sanitários e 18,4\% em aterros controlados). Em 63,6\% dos municípios, o lixo doméstico, quando recolhido, é simplesmente transportado para depósitos irregulares, os chamados "lixões". No caso dos "lixões", não possuem nenhum tipo de controle, quer quanto ao tipo de resíduos recebidos, quer em relação às medidas de segurança necessárias, para minimizar ou evitar emissões de poluentes para o meio ambiente.

A disposição inadequada dos resíduos sólidos promove a contaminação do solo, do ar e das águas superficiais e subterrâneas, além da proliferação de vetores de doenças, influenciando negativamente a qualidade ambiental e a saúde da população; portanto, esta prática deve ser evitada.

A contaminação do solo ocorre por intermédio da infiltração dos líquidos percolados (chorume), gerados pela passagem da água através dos resíduos sólidos em processo de decomposição. O chorume possui elevada carga de poluentes orgânicos e inorgânicos e, ao entrar em contato com o solo, pode modificar, de forma intensa, suas características físicas, 
químicas e biológicas, bem como as das águas subterrâneas, caso consiga alcançá-las.

A matéria orgânica presente no chorume tem importância na complexação e transporte de metais pesados e na retenção de alguns contaminantes orgânicos. Aliado a que a matéria orgânica natural presente no solo, além de participar desses processos pode aumentar a concentração de constituintes do chorume na solução do solo e, conseqüentemente, nas águas. Desta forma, tanto a matéria orgânica do chorume quanto a do solo e a associação das duas, podem limitar ou tornar inviável o uso dos recursos naturais solo e água.

A matéria orgânica natural do solo apresenta maiores concentrações nas camadas superficiais $(<1,0 \mathrm{~m})$ e diminui com o aumento da profundidade. Ante a sua distribuição no solo, análises da matéria orgânica em amostras de solos contaminados por chorume de resíduos sólidos domésticos podem ser utilizadas para identificar a pluma de contaminação. Caso sejam encontrados teores de matéria orgânica em áreas sujeitas à influência do chorume (em média profundidade) superiores aos teores da composição química natural dos solos, ou seja, nas áreas não-afetadas, pode ser indicativo de que a pluma de contaminação do chorume já tenha migrado e afetado o solo, até determinada profundidade.

Contudo, apesar da sua importância, a matéria orgânica tem sido muito pouco analisada em solos sujeitos à contaminação devido à disposição inadequada de resíduos sólidos domésticos. Entre os poucos trabalhos identificados, estão os de Barbosa (1994), Sisinno (1995) e Heitzmann Jr. (1999) que analisaram a concentração da matéria orgânica no solo em função do teor do carbono orgânico, utilizando-se do método titulação após oxirredução por via úmida - conhecido como método Walkley-Black, e os estudos de Oliveira \& Jucá (1999) que analisaram a matéria orgânica pelo teor de sólidos voláteis, utilizando o método descrito pela WHO (1978) baseado na ignição.

Entretanto, não foram localizados estudos que avaliassem a eficiência desses métodos na determinação da matéria orgânica em amostras de solos sujeitas à influência do chorume. Esta preocupação é baseada no fato do método Walkley-Black ter sido desenvolvido para análises agrícolas (considerandose a matéria orgânica natural) mas está sendo utilizado para analisar amostras de solo contendo concentrações de matéria orgânica acrescidas de outras fontes, como no caso do chorume. Assim, o método pode não ser adequado para analisar amostras de solo desse tipo, fornecendo resultados imprecisos.

Buscando-se contribuições neste sentido, o presente trabalho teve, como objetivo principal, verificar o potencial do método titulação após oxirredução por via úmida - WalkleyBlack (Nelson \& Sommers, 1982) para determinação da matéria orgânica em amostras de solos contaminadas por chorume de resíduos sólidos domésticos.

\section{MATERIAL E MÉTODOS}

A metodologia empregada consistiu de ensaios de contaminação por chorume, em laboratório, em dois solos inorgânicos similares (Latossolo Vermelho). A matéria orgânica presente no percolado foi determinada pelas análises de DBO,
DQO e COT e o teor da matéria orgânica presente no solo natural e contaminado por meio das análises de carbono orgânico (CO).

As amostras de solo indeformadas foram coletadas em duas áreas experimentais pertencentes à Universidade de Brasília UnB, localizadas no DF. Na área experimental de Geotecnia, de um mesmo ponto foram retiradas duas amostras, na profundidade de 1,0 m (Amostra I) e 1,50 m (Amostra II); já na área experimental de Biologia, foi coletada apenas uma amostra, na profundidade de $1,0 \mathrm{~m}$.

As amostras de chorume utilizadas foram coletadas do experimento de uma dissertação de mestrado que, na época, estava sendo desenvolvida no Laboratório de Geotecnia da UnB. Este chorume se originava de resíduos domésticos predominantemente orgânicos - 92\% da composição gravimétrica com baixa contaminação de metais.

Para a realização dos ensaios montou-se um aparato experimental para a contaminação do solo composto, basicamente, de uma placa circular de diâmetro 2", confeccionada em chapa PVC branca contendo 21 orifícios, objetivando-se distribuir uniformemente o volume do chorume. A placa era acoplada a um cilindro de $6,0 \mathrm{~cm}$ de comprimento e 2" de diâmetro, confeccionado em tubo PVC branco. Neste cilindro era introduzida a amostra de solo indeformada. Uma pipeta de vidro graduada em $20 \mathrm{~mL}$ era o instrumento utilizado para injeção do chorume na amostra de solo. Alguns acessórios complementares foram necessários: garra, pipetador e prato de alumínio. A Figura 1 ilustra o aparato experimental utilizado para contaminação do solo com o chorume.
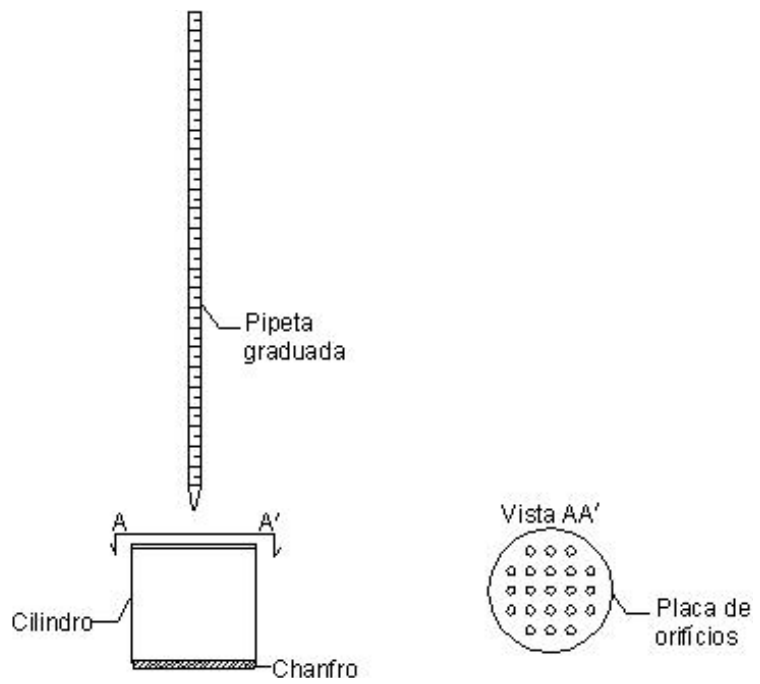

Figura 1. Desenho esquemático do aparato experimental para contaminação

Antes do processo de contaminação, amostras de solo indeformadas eram moldadas manualmente no bloco de solo, e coletadas amostras de solo deformadas para determinação do teor de umidade e do teor da matéria orgânica, pelas análises do CO com a amostra ainda úmida. A outra parcela era colocada em um prato de alumínio e posta para secar à sombra, em temperatura ambiente, pelo período de 5 dias, após o qual eram realizadas novamente análises do $\mathrm{CO}$ com as amostras secas. Logo depois do procedimento para determinação do teor de 
umidade das amostras de solo natural, eram efetuados os ensaios de contaminação das amostras indeformadas, realizados da seguinte forma: inicialmente, o cilindro com peso definido com a amostra de solo era pesado em balança de precisão; em seguida, era fixado firmemente pela garra acoplada a uma haste com, na parte inferior, um prato de alumínio; posteriormente, introduzia-se o volume de $15 \mathrm{~mL}$ de chorume concentrado dentro do cilindro, por meio de pipeta graduada direcionada nos orifícios. O volume do chorume era distribuído uniformemente em quantidade aproximada por todos os orifícios da placa, de forma a se obter maior homogeneização do percolado dentro da amostra de solo.

Após o processo de contaminação, o período de $30 \mathrm{~min}$ foi reservado para a acomodação do chorume na amostra de solo; em seguida, pesou-se novamente o cilindro e se retirou toda a amostra de solo com uma colher em aço inox, colocando-a no prato de alumínio; depois, a amostra foi homogeneizada manualmente com a colher. Ao final do procedimento, uma parte da amostra era retirada para a determinação do teor de umidade, outra parcela era passada na peneira de abertura $0,50 \mathrm{~mm}$, para a realização das análises de $\mathrm{CO}$, e o restante permanecia no prato para secar em temperatura ambiente, pelo período de 5 dias. Após a secagem, também eram realizadas novamente as análises de $\mathrm{CO}$, objetivando-se a comparação dos resultados entre amostras de solo secas e úmidas. A Figura 2 ilustra o processo de contaminação do solo.

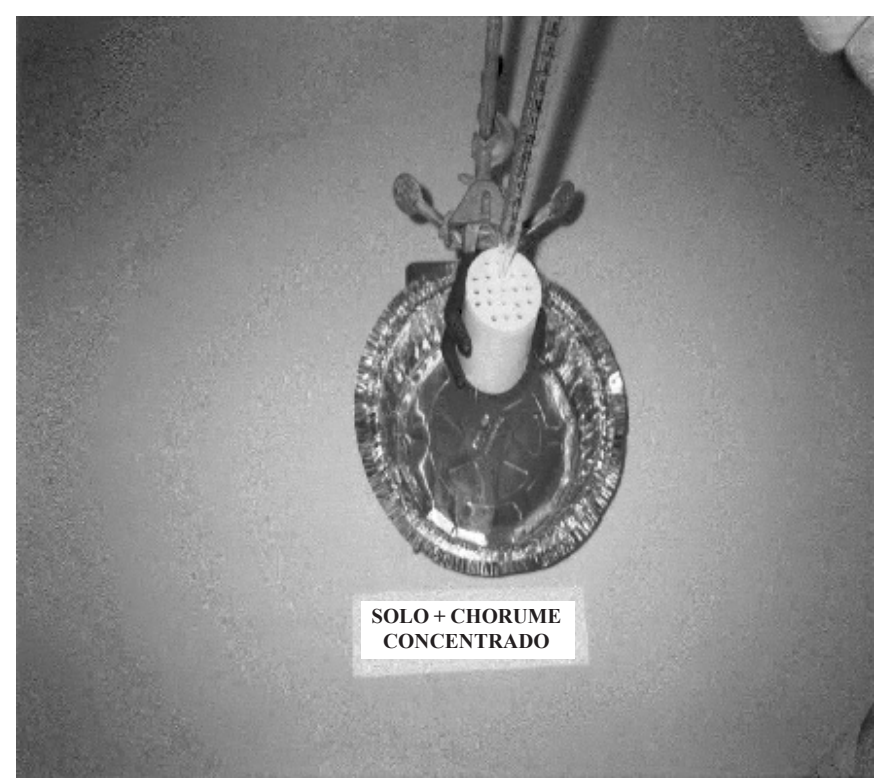

Figura 2. Detalhe do processo de contaminação do solo pelo chorume

A realização das análises do carbono orgânico nas amostras de solo secas e úmidas, visou verificar a possível perda de matéria orgânica durante o processo de secagem das amostras contaminadas.

Para cada análise feita em amostra contaminada fez-se também uma análise de $\mathrm{CO}$ em amostra do solo sem contaminação, para determinação da matéria orgânica naturalmente presente no solo.

A metodologia para o desenvolvimento da análise e o cálculo para a determinação do CO seguiram os procedimentos descritos por Nelson \& Sommers (1982) e Oliveira et al. (2000). Inicialmente, pesou-se em triplicata $0,5 \mathrm{~g}$ de solo (úmido ou seco) passado na peneira de malha $0,5 \mathrm{~mm}$; em seguida, transferiu-se o solo para um frasco erlenmeyer de $500 \mathrm{~mL}$. Adicionaram-se exatamente $10 \mathrm{~mL}$ de $\mathrm{K}_{2} \mathrm{Cr}_{2} \mathrm{O}_{7} 1 \mathrm{Ne}$, rapidamente, $20 \mathrm{~mL}$ de $\mathrm{H}_{2} \mathrm{SO}_{4}$ concentrado; de imediato, agitou-se o frasco, para proporcionar a mistura do solo com os reagentes, por um período aproximado de $1 \mathrm{~min}$; em seguida, a mistura foi deixada em repouso pelo tempo aproximado de $40 \mathrm{~min}$. Então, adicionaram-se $150 \mathrm{~mL}$ de água destilada e se filtrou a solução em papel filtro, utilizando-se bomba vácuo para acelerar o processo adicionando-se, depois, mais $50 \mathrm{~mL}$ de água destilada sobre o papel filtro para a completa remoção da solução no mesmo; logo após introduziram-se, na solução, $10 \mathrm{~mL}$ de $85 \%$ $\mathrm{H}_{3} \mathrm{PO}_{4}$ e $1,0 \mathrm{~mL}$ do indicador difenilamina, seguido de titulação com $\mathrm{Fe}_{2} \mathrm{SO}_{4} 0,5 \mathrm{~N}$ até a passagem da cor violeta para a verde (neste ponto, o excesso de dicromato é totalmente consumido pela reação). Paralelamente, o mesmo procedimento foi feito para a prova em branco, com exceção da introdução do solo. É importante salientar que não foi incluído, na determinação do $\mathrm{CO}$, o fator de correção de 1,3 para corrigir a parcela não-oxidada do carbono orgânico do solo. Seguindo as sugestões de Nelson \& Sommers (1982) o CO não foi convertido para matéria orgânica pelo fator de correção de 1,72. Os resultados do CO obtidos nas amostras de solo foram analisados em termos de matéria orgânica.

O cálculo para a determinação do CO seguiu os procedimentos descritos por Nelson \& Sommers (1982) e Oliveira et al. (2000).

A determinação da matéria orgânica introduzida no solo pelo chorume foi feita utilizando-se a análise de COT e o volume de chorume empregado na contaminação de cada amostra.

Determinaram-se dois valores de CO para cada amostra: o valor encontrado e o valor esperado. $\mathrm{O}$ valor encontrado foi aquele diretamente determinado pelo método Walkley-Black nas amostras contaminadas, e o esperado foi determinado através de cálculo em que ao $\mathrm{CO}$ determinado para a amostra de solo sem contaminação, foi adicionado o valor de carbono orgânico do chorume introduzido.

No que se refere ao tratamento dos dados, estes foram avaliados mediante parâmetros estatísticos como média aritmética, desvio padrão, coeficiente de variação, coeficiente de correlação (r) e análise de regressão linear.

\section{RESULTADOS E DISCUSSÃO}

\section{Caracterização dos solos}

Os solos estudados são classificados como Latossolo Vermelho de textura argilosa. A caracterização física do solo A e do solo B encontra-se na Tabela 1.

$\mathrm{Na}$ análise de granulometria pode-se constatar que os dois solos são formados, predominantemente, por granulação tamanho argila com menor fração de silte; entretanto, o solo B apresenta valores maiores das duas granulações. 
Tabela 1. Característica física do solo A e solo B

\begin{tabular}{lcc}
\hline Característica Física & Solo A & Solo B \\
\hline Umidade natural $\left(\mathrm{m}^{3} \mathrm{~m}^{-3}\right)$ & $17,9 \times 10^{-2}$ & $37,4 \times 10^{-2}$ \\
Umidade higroscópica $\left(\mathrm{m}^{3} \mathrm{~m}^{-3}\right)$ & $1,44 \times 10^{-2}$ & $2,33 \times 10^{-2}$ \\
Densidade real dos grãos $\left(\mathrm{kg} \mathrm{dm}^{-3}\right)$ & 2,64 & 2,65 \\
Massa específica aparente seca $\left(\mathrm{kg} \mathrm{dm}^{-3}\right)$ & 1,05 & 0,88 \\
Limite de liquidez $\left(\mathrm{m}^{3} \mathrm{~m}^{-3}\right)$ & $38,0 \times 10^{-2}$ & $49,0 \times 10^{-2}$ \\
Limite de plasticidade $\left(\mathrm{m}^{3} \mathrm{~m}^{-3}\right)$ & $28,0 \times 10^{-2}$ & $39,0 \times 10^{-2}$ \\
Índice de plasticidade $\left(\mathrm{m} \mathrm{m}^{3} \mathrm{~m}^{-3}\right)$ & $10,0 \times 10^{-2}$ & $10,0 \times 10^{-2}$ \\
Porosidade $\left(\mathrm{m}^{3} \mathrm{~m}^{-3}\right)$ & $60,0 \times 10^{-2}$ & $67,0 \times 10^{-2}$ \\
Índice de vazios & 1,51 & 2,01 \\
Fração de areia grossa $\left(\mathrm{g} \mathrm{kg}^{-1}\right)$ & $1,3 \times 10$ & $1,5 \times 10$ \\
Fração de areia média $\left(\mathrm{g} \mathrm{kg}^{-1}\right)$ & $11,2 \times 10$ & $6,3 \times 10$ \\
Fração de areia fina $\left(\mathrm{g} \mathrm{kg}^{-1}\right)$ & $23,6 \times 10$ & $8,8 \times 10$ \\
Silte $\left(\mathrm{g} \mathrm{kg}^{-1}\right)$ & $13,2 \times 10$ & $22,4 \times 10$ \\
Argila $\left(\mathrm{g} \mathrm{kg}^{-1}\right)$ & $50,6 \times 10$ & $61,0 \times 10$ \\
\hline
\end{tabular}

O teor de umidade natural nos dois solos é bastante diferente, apresentando variação em torno de 20\%. Quanto à umidade higroscópica, o solo B também apresentou teor mais elevado, valor este previsto, tendo em vista ser o solo mais argiloso.

Os ensaios que determinam o índice de vazios e a porosidade apresentaram valores bastante elevados, índice de vazios superior a 1,5 e porosidade superior a $60 \%$.

\section{Caracterização do chorume}

Em cada ensaio de contaminação buscou-se utilizar amostras de chorume coletadas em datas diferentes, de forma a se realizarem os ensaios com amostras de diferentes teores de matéria orgânica. A Tabela 2 apresenta os parâmetros analisados no chorume.

De acordo com a Tabela 2, constata-se que os teores de COT nas amostras de chorume apresentam resultados relativamente altos e com diferenças de um ensaio para outro, variando de uma faixa de 17.780 a $40.590 \mathrm{mg} \mathrm{C} \mathrm{L}^{-1}$.

Tabela 2. Parâmetros analisados no chorume

\begin{tabular}{|c|c|c|c|c|}
\hline \multirow{3}{*}{ Ensaios } & \multicolumn{4}{|c|}{ Parâmetros* } \\
\hline & \multirow{2}{*}{$\mathrm{pH}$} & $\mathrm{DBO}$ & DQO & \multirow{2}{*}{$\frac{\mathrm{COT}}{\mathrm{mg} \mathrm{C} \mathrm{L}^{-1}}$} \\
\hline & & \multicolumn{2}{|c|}{$\left(\mathrm{mg} \mathrm{O}_{2} \mathrm{~L}^{-1}\right)$} & \\
\hline 1 & 4,3 & - & 48.437 & 20.350 \\
\hline 2 & 4,6 & - & 87.310 & 34.000 \\
\hline 3 & 4,3 & - & 46.411 & 24.730 \\
\hline 4 & 4,3 & - & 52.570 & 23.540 \\
\hline 5 & 4,3 & 30.000 & 36.211 & 40.590 \\
\hline 6 & 4,3 & 33.300 & 42.557 & 18.500 \\
\hline 7 & 5,4 & - & 50.888 & 31.850 \\
\hline 8 & 4,7 & - & 59.140 & 39.100 \\
\hline 9 & 4,8 & 53.700 & 108.903 & 35.270 \\
\hline 10 & 4,8 & - & 69.100 & 25.320 \\
\hline 11 & 4,8 & 40.000 & 62.000 & 28.160 \\
\hline 12 & 4,8 & - & 57.000 & 22.050 \\
\hline 13 & 4,7 & - & 102.400 & 34.780 \\
\hline 14 & 4,7 & - & 67.100 & 25.180 \\
\hline 15 & 4,9 & - & 77.500 & 28.590 \\
\hline 16 & 5,1 & - & 71.000 & 26.630 \\
\hline 17 & 5,0 & - & 43.400 & 17.780 \\
\hline 18 & 4,8 & - & 47.200 & 21.230 \\
\hline 19 & 4,8 & - & 53.800 & 21.320 \\
\hline 20 & 4,8 & - & 47.800 & 19.820 \\
\hline Média Aritmética & 4,7 & 39.250 & 61.536 & 26.940 \\
\hline Desvio Padrão & 0,3 & 10.493 & 19.756 & 6.893 \\
\hline
\end{tabular}

* DBO - Demanda biológica de oxigênio; DQO - Demanda química de oxigênio

COT - Carbono orgânico total
Os valores da DQO encontrados para o chorume foram bastante elevados, variando na faixa de 36.211 a $108.903 \mathrm{mg} \mathrm{L}^{-1}$, o mesmo encontrado para DBO, com teores na faixa de 30.000 a $53.700 \mathrm{mg} \mathrm{L}^{-1}$.

As elevadas concentrações de COT, DQO e DBO, a relação DBO/DQO permanecendo entre 0,5 a 0,8 e o pH ácido $(4,3$ a 5,4$)$ das amostras de chorume fornecem subsídios para que este seja caracterizado como típico de aterros sanitários jovens (Tchobanouglous et al. ,1993). Este resultado já era esperado, uma vez que o chorume era proveniente de resíduos sólidos domésticos constituídos basicamente de matéria orgânica $(92,1 \%)$ e oriundo de experimento desenvolvido em curto período de tempo (7 meses).

\section{Matéria orgânica no solo contaminado por chorume}

As Figuras 3 e 4 mostram os resultados dos teores de $\mathrm{CO}$ para as diversas amostras (valor encontrado e valor esperado de CO), para os dois solos (solo A e solo B) com as análises pelo método Walkley-Black feitas com solo úmido e solo seco. Também são apresentados as equações das retas ajustadas aos pontos e os coeficientes de correlação (r).

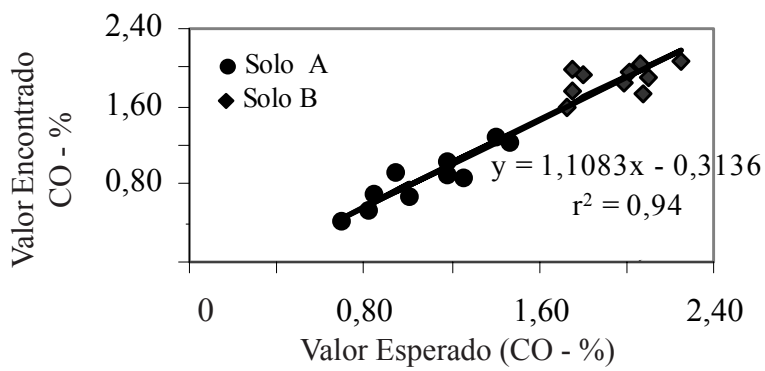

Figura 3. Valores de carbono orgânico $(\mathrm{CO})$ em solos úmidos contaminados com chorume. Relação entre valores encontrados (determinação direta pelo método Walkley-Black) e valores esperados (CO do solo sem contaminação, determinados pelo método Walkley-Black, acrescidos do COT do chorume introduzido)

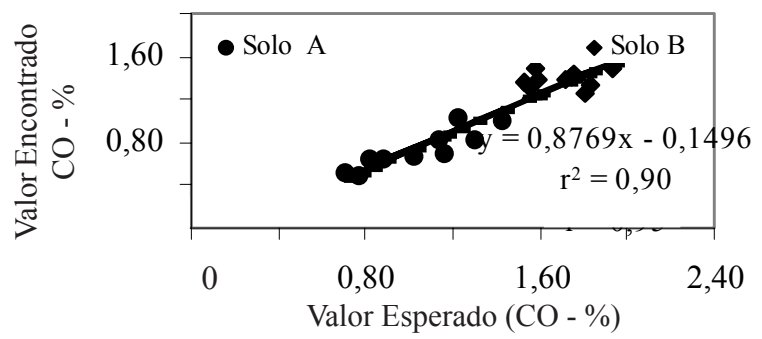

Figura 4. Valores de carbono orgânico (CO) em solos secos contaminados com chorume. Relação entre valores encontrados (determinação direta pelo método Walkley-Black) e valores esperados (CO do solo sem contaminação, determinados pelo método Walkley-Black, acrescidos do COT do chorume introduzido)

Analisando-se as Figuras 3 e 4, nota-se boa correlação entre os valores esperados e os encontrados para o $\mathrm{CO}$ do solo, após contaminação com chorume. Esta boa correlação é encontrada tanto para as análises feitas com solo seco como para as realizadas com solo úmido, mostrando que a eventual 
perda de matéria orgânica durante o processo de secagem pode ser desconsiderada. Também se constata que os dois solos (solo A e solo B) tiveram comportamento similar, que pode ser explicado pela mesma regressão linear.

A conseqüência prática desse resultado é permitir que se analise contaminação de área por chorume, desde que seja possível uma amostra de solo do local sem contaminação. De qualquer maneira, para determinação quantitativa dos teores de CO introduzidos pelo chorume com este procedimento, será necessário fazer curva de calibração.

\section{CONCLUSÕES}

1. O método Walkley-Black mostra-se com potencial para determinação da matéria orgânica em amostras de solo contaminadas pelo chorume.

2. A perda de carbono orgânico na etapa de secagem do solo aparenta não ser significativa, indicando a possibilidade de simplificar o procedimento de análise.

\section{LITERATURA CITADA}

Barbosa, M.C. Investigação geoambiental do depósito de argila sob o aterro de resíduos urbanos de Gramacho, RJ. Rio de Janeiro: UFRJ, 1994. 300p. Tese Doutorado

Heitzmann Jr., J.F. Alterações na composição do solo nas proximidades de depósitos de resíduos domésticos na bacia do Rio Piracicaba. São Paulo: Associação Brasileira de Geologia de Engenharia - ABGE, 1999. 65p. Síntese de Tese nº 9
IBGE - Instituto Brasileiro de Geografia e Estatística. Pesquisa nacional de saneamento básico 2000. Rio de Janeiro: Instituto Brasileiro de Geografia e Estatística, 2002. 397p.

Nelson, D.W.; Sommers, L.E. Total carbon, organic carbon, and organic matter. In: Page, A.L.; Miller, R.H.; Keeney, D.R. (ed.) Methods of soil analysis - chemical and microbiological properties. Part 2, 2 ed. Madison: American Society of Agronomy e Soil Science Society of America, 1982. cap. 29, p.539-579.

Oliveira, F.J.S.; Jucá, J.F.T. Estudo da contaminação do subsolo da região do aterro de resíduos sólidos de Muribeca, PE. In: Congresso Brasileiro de Geotecnia Ambiental - REGEO'99, 4, 1999, São José dos Campos, p.456-461.

Oliveira, S.A.; Mesquita Filho, M.V.; Souza, A.F.; Fontes, R.R. Análises químicas de solo e de calcário para fins de fertilidade do solo. Brasília: Editora Universidade de Brasília, 2000. 31p.

Sisinno, C.L.S. Estudo preliminar da contaminação ambiental em área de influência do aterro controlado do Morro do Céu (Niterói, RJ). Rio de Janeiro: Escola Nacional de Saúde Pública da Fundação Oswaldo Cruz, 1995. 101p. Dissertação Mestrado

Tchobanouglous, G.; Theisen, H.; Vigil, S.A. Integrated solid waste management - engineering principles and management issues. New York: McGraw-Hill, 1993. 978p.

WHO - World Health Organization. International Reference Center for Wastes Disposal. Methods of analysis of sewage sludge solid wastes and compost. Switzerland, 1978. 